\title{
Nuclear sciences: A unique contribution to the betterment of the human condition
}

\author{
W. BURKART ${ }^{* \dagger}$ \\ Department of Nuclear Sciences and Applications, IAEA, \\ Schwarzenbergplatz 6/T 18, 1030 Vienna
}

\section{A short and partially tainted history}

The sciences and applications of ionizing radiation and radioactivity only started in earnest with the discovery of X-rays by Wilhelm Roentgen in 1895, the discovery of radioactivity by Henri Bequerel in 1896, and the isolation and description of the two new radioactive elements polonium and radium from uranium ore pitchblende by Pierre and Marie Curie shortly thereafter. Until the end of the $19^{\text {th }}$ century the powers of unstable atoms had remained hidden from all cultures, fluorescent glasses containing uranium salts being an exception. Even during early industrialization when silver miners encountered pitchblende ${ }^{1}$, an ore rich in uranium, this only meant misfortune, the end of silver streaks.

The study of radioactivity and ionizing radiation was an important driver in the development of physical, chemical and biological sciences in the $20^{\text {th }}$ century, both for the elucidation of atomic and nuclear forces, and the development of analytical and imaging tools. Albeit there were few industrial or medical applications beyond X-ray imaging in the early years of the $20^{\text {th }}$ century, the public of the industrialized world developed a love

\footnotetext{
*IAEA former Deputy Director General.

${ }^{\dagger}$ E-mail: werner. burkart@tele2. at

1 "Pech" in German has two meanings, pitch or bad luck. Hence a proper translation would have been "bad luck glitter".
}

This is an Open Access article distributed under the terms of the Creative Commons Attribution License 2.0, which permits unrestricted use, distribution, and reproduction in any medium, provided the original work is properly cited 
affair with this exotic new field of knowledge and phenomena. It started with fair attractions like viewing one's own hand bones or counting the coins in the closed purse, and culminated in uranium, thorium and radium laced beauty creams and medications. First protective measures by governmental bodies concentrated on assuring that the concoctions contained the full amount of the expensive radioactivity promised in the advertisement.

During the first half of the last century, radiation medicine developed to become an indispensable diagnostic tool for many pathological conditions, and radiation therapy of cancer proved its use in a struggle which even now is too often lost. Some excesses occurred with the irradiation of enlarged thymus glands in children, or the radiation induction of epilation (hair loss) to combat Tinea capitis, a superficial fungal infection of the scalp, mostly in pre-pubertal children.

In the thirties and early forties, pioneering physicists like Otto Hahn, Lise Meitner, Enrico Fermi and Leo Szilard laid the theoretical and practical groundwork to harness the energy of the atom, the fission energy of heavy actinide elements. The nuclear energy from splitting the heaviest or fusing the lightest elements on earth yields five to six orders of magnitude more energy per fission or fusion event than the differential energy of chemical bonds set free during the oxidation of hydrocarbons in combustion. Predictably but unfortunately, both scientists and politicians too readily explored the potential of this nuclear energy for the battle ground of World War II. They met with scientific success with the first test explosion in New Mexico in 1945. Shortly afterwards, the apocalyptic impact of a ${ }^{235}$ uranium and a ${ }^{238}$ plutonium fission bomb dropped on the Japanese cities of Hiroshima and Nagasaki, respectively, forced the end of World War II. Only fifty years after the emergence of nuclear sciences, something considered earlier on a curiosity had provided humankind with the ultimate power to destroy civilisation and higher forms of life from planet earth. Nuclear had lost its innocence, especially since the emerging cold war led to an arms race dominated by nuclear weaponry. The technical breakthrough to hydrogen bombs (fission-fusion and fission-fusion-fission bombs) allowed the posturing with atmospheric bomb tests with a maximal yield of the equivalent of $60 \mathrm{Mt}$ of TNT, or a yield of approximately 4,000 times the Hiroshima bomb.

However, the potential of fission and fusion as a source of heat and electricity was not lost and civilian power programmes sprung up in many industrialized countries. Through the "Atoms for Peace" initiative in 1953 and the foundation of the International Atomic Energy Agency (IAEA) in 
1957, the world powers rose above the cold war attitude and undertook genuine efforts to keep the genie in the bottle, at least for newcomers. The potential of nuclear power as a reliable and affordable source of electricity was established in the sixties. Today countries like France, Sweden, Switzerland or Belgium produce from 40 to $80 \%$ of the electricity through fission reactors. In 1986, the destructive power of the atom was unleashed again; this time by human negligence and unsafe reactor design features. A power excursion accident led to the destruction of unit four of the Chernobyl power station during an poorly executed test intended to improve the safety of the reactor. A considerable part of the highly radiotoxic inventory of a large fission reactor was released into the environment. The chimney effect of the ensuing graphite fire and the absence of local rain led to a measurable contamination of large parts of Europe and adjacent areas. Even when some extreme claims of the radiological effects of Chernobyl can be discounted, the human suffering mainly from thousands of already occurred thyroid cancers in children, the projected protracted cancer risk in more affected cohorts in Belarus, Ukraine and the Russian Federation, and the socio-economic damage from evacuation and land use restriction put the case for nuclear power into question. Only the economics of fossil fuels and the recent recognition of the threat of climate change gave nuclear power a second life which will have to be driven by safe, secure and efficient novel reactors and fuel cycle concepts.

An important and unique contribution of radioactive and stable isotopes concerns the understanding of the environment. Be it live, organic and inorganic inventories or processes, nuclear tracers are available to study any developments, be it present, in a human history or geological time context. From the heat and mass flows of ocean currents to the age of the Sindone di Torino, natural radionuclides provide tracers with half-lives of a fraction of a day to primordial radionuclides with half-lives measured in billions of years. Together with the analysis of ratios of stable isotopes, the unfortunate Ice Man (Oetzi) who perished at the border between Italy and Austria reveals many of his secrets. The mummy's isotopes do not only yield its age $\left({ }^{14} \mathrm{C}\right.$ dating $)$ but through isotope analysis of bone compartments with different remodelling dynamics, the locations where he spent his youth and other periods of his life are traceable. To protect our fragile habitat in times of rapid development and economic growth can only work through a better understanding of our environment. From climate history to the management of scarce water resources, nuclear analytics and forensics are central to "knowing before acting". 


\section{The UN Millennium Development Goals and the role of nuclear}

The World population has reached 6.8 billion and is still growing 80 million a year, an additional Germany every twelve months. Food and water security, shelter, good health, access to education and a safe environment are fundamental elements for our quality of life. Yet these basic human needs as put down in the UN Millennium Development Goals ${ }^{2}$ are still not available to too many people on this globe. This calls for sustainable and sciencebased industrial development at an immense scale to provide the economic resources needed to raise the standard of living globally. In technologically advanced societies nuclear technologies have a much larger role to play in human development than just providing energy. Nuclear technologies offer unique tools in the quest for sustainable development and are often the best approach to gather technological and scientific information and provide solutions that would not otherwise be possible or practical. They are used to diagnose and treat disease, breed better crops and fight insect pests; assess sources of fresh water and monitor pollution. Radioactive and stable isotopes can be used to "label" materials under study. As they can be identified and quantified at very low concentrations, labelling is often used in diagnostic medical tests, in studies of underground sources of water, and to trace pollutants, such as heavy metals and pesticides. Isotopes are also used in nutritional studies to follow the metabolism of vitamins and trace minerals in food supplements. Other nuclear techniques utilise radiation, to kill cancer cells, sterilize tissue grafts for burn victims, protect food against disease-causing pathogens, induce favourable genetic changes in plants, or scan body organs for anatomical or functional aberrations.

Table 1 shows some hardware investments needed to provide for the additional people per year which equals the population of Germany. At the living standard of Europe, the annual addition of housing space would be an area of the size of Luxembourg and the new railway tracks would be close to the Earth circumference. $\mathrm{CO}_{2}$ production in Germany is 9.7 tons per capita and year which would convert into the injection into the atmosphere of an additional $780 \cdot 10^{6}$ tons of $\mathrm{CO}_{2}$ per year from the 80 million people added to the world population in a single year. This is not sustainable and even if the rich North would reduce its $\mathrm{CO}_{2}$ foot print considerably, new forms of energy have to be deployed quickly. If we go through the UN list of Millennium Development Goals, it becomes evident that to cover

\footnotetext{
${ }^{2}$ http://www.un.org/millenniumgoals/bkgd.shtml
} 
Table 1: Annual additional infrastructure needed for present day world population growth and projected global inventory, assuming European standard of living for all.

\begin{tabular}{|l|r|r|}
\hline & $\begin{array}{c}\text { Global Annual Growth } \\
\text { or "One Germany" }\end{array}$ & $\begin{array}{c}\text { World Projected } \\
7 \text { billion people }\end{array}$ \\
\hline Highways [km] & 12600 & 1100000 \\
\hline Roadways [km] & 41300 & 3610000 \\
\hline Railways [km] & 34000 & 2870000 \\
\hline Living space $\left[\mathrm{km}^{2}\right]$ & 2400 & 210000 \\
\hline Electricity production [GW] & 637 & 55700 \\
Number of power plants needed if covered by: & 160 & 14000 \\
- Fossil fuel power plants $[500 \mathrm{MW}$, & 400000 & 35000000 \\
- Windmills $[1 \mathrm{MW}]^{a}$, equals & 80 & 7000 \\
\hline
\end{tabular}

a Assuming an availability factor of 0.2 .

even the most basic needs, the energy poor have to be provided specifically with electricity. Food security, industrial production, education, health, communication and transport all depend crucially on electricity. Table 2 lists the major energy sources, supplies and consumptions for today and the future. The strong reliance on fossil fuels will have to be substituted both because of the greenhouse gas problem and exhaustion of resources.

\section{$3 \quad$ Electricity for an energy hungry world}

Regretfully much of the world's energy need is currently being produced and consumed in ways that cannot be sustained. Today and in the short run, only hydro and nuclear power offer reliable and affordable low-carbon electricity, the former unfortunately with little potential for growth, especially in densely populated regions. The carbon foot print of present day fission reactors is at the low level of large hydro and wind $\left(10 \mathrm{~g}\right.$ of $\mathrm{CO}_{2}$ per $\mathrm{kWh}$ or $1 \%$ of coal power which is in the range of $1,000 \mathrm{~g}$ life cycle emissions), and better than photovoltaic. Unfortunately, conventional uranium reserves and once through fuel use would prevent nuclear from taking a central role for energy and electricity production for several centuries into the future. However, sound concepts exist to make nuclear energy practically inexhaustible for thousands of years to come. They are mostly based on proven technology or the extension thereof, and - with the exception of fusion - can provide in one or two decades, given strong political leadership: 
Table 2: Global supply and consumption of major present day energy sources [ETJ $=10^{18} \mathrm{~J}$. Note that for wind, hydro and nuclear, the values are for electricity, for fossil fuels and biomass for heat (IPCC estimates).

\begin{tabular}{|l|c|c|c|}
\hline Energy Source & $\begin{array}{c}\text { Estimated supply } \\
{[\text { ETJ] }}\end{array}$ & $\begin{array}{c}\text { Consumption } \\
{[\text { ETJ/year] }}\end{array}$ & $\begin{array}{c}\text { Share of Supply } \\
{[\%]^{*}}\end{array}$ \\
\hline Coal & $>100000$ & 120 & 25 \\
\hline Gas & $>30000$ & 105 & 22 \\
\hline Oil & 45000 & 163 & 33 \\
\hline Biomass & $250 / \mathrm{yr}$ & 46 & 9 \\
\hline Wind & $600 / \mathrm{yr}$ & 1 & 0.2 \\
\hline Hydro & $62 / \mathrm{yr}$ & 26 & 5 \\
\hline Fission & $>220000$ & 26 & 5 \\
\hline Fusion & 5000000000 & 0 & 0 \\
\hline
\end{tabular}

1. The introduction of new reactor concepts operating at much higher temperatures of up to $800^{\circ} \mathrm{C}$; this would increase efficiency and create the option of hydrogen production, a potential clean fuel for transportation.

2. Reprocessing of spent nuclear fuel, i.e. the conversion of the majority of non-fissile ${ }^{238}$ uranium into fissile ${ }^{239}$ plutonium will increase the yield as compared to once through systems by a factor of 50 and more.

3. The burning of abundant ${ }^{232}$ thorium after conversion to fissile ${ }^{233}$ uranium, a concept developed in detail by Italian Nobel laureate Carlo Rubbia and ready to be tested in a large experimental reactor.

4. Harnessing uranium from sea water which - even at the very low concentration of $3.3 \mathrm{mg}$ per $\mathrm{m}^{3}$ (3.3 ppb or $3.3 \mathrm{t}$ per $\mathrm{km}^{3}$ of seawater) would again extend fuel reserves by orders of magnitude.

5. Fusion energy relying on practically inexhaustible elements for fuel, and being able to provide the neutrons to drive the breeding of ${ }^{239}$ plutonium and ${ }^{233}$ uranium needed for 2 . and 3 .

Given the stakes in feeding an energy-hungry world, even the most elusive task in the list, the creation of the heat and confinement for controlled and affordable fusion on earth is of great importance. The 15 billion $€$ to be spent on ITER, an experimental fusion reactor being built in Cadarache, France, as a precursor to a first fusion power plant DEMO, is a small price 
compared to the crude oil import bills for fossil fuels of larger countries. These monthly imports for the US only amount to the same sum as the ITER costs over 20 years. At this point, an ethical argument might be raised. Humankind mastered fusion for more military purposes with the hydrogen bomb already more than 50 years ago. It would be more than appropriate to master fusion for peaceful electricity production at least until 2052 , the centennial of the first hydrogen bomb explosion in Operation Ivy on November 1, 1952, on the Enewetak Atoll of the Marshall Islands.

\section{Safety, security and safeguards}

In a constructive response to the somewhat tainted history of nuclear in war and power, the international community has developed a comprehensive framework of protection philosophies and regulations to use the power of the atom in a safe and sustainable way, and to prevent further military or terrorist use. Led by international bodies like the IAEA, the NEA/OECD and regional groups, and implemented by national regulators, most occupational and non-occupational exposures and the radiological impact on the environment have been reduced to levels far below those received from natural sources of radiation exposure, such as the sun and terrestrial radionuclides. Despite the human suffering and financial losses of Chernobyl and Three Mile Island, these experiences have made nuclear power production safer. The challenges from the inherent genotoxicity of ionizing radiation and the complexities of protection against invisible and odourless, but often persistent radioactivity, have led to a comprehensive safety culture which is pioneering developments in other areas of industrial production and transport. It may sound somewhat preposterous, but as the task of managing large river systems in Egypt and Mesopotamia stimulated societal and cultural development, the "triple S" of safety, security and safeguards has changed our thinking and political interactions far beyond the nuclear field. Even in the most difficult phases of the cold war, the big powers sat together to keep the nuclear genie in the bottle, and from the positive experiences of tackling this issue, went on to seek solutions to the root problems of proliferation.

When discussing the potential of nuclear power to satisfy basic human needs of the world, as put down in the UN Millennium Development Goals, the risk of proliferation, the potential emergence of atomic bombs out of civilian applications has to be considered. This notion is also driven by public perception of nuclear power plants as a kind of tamed atomic bombs. 
Table 3: Weapon states; first test or weaponisation as compared to the onset of nuclear electricity production.

\begin{tabular}{|l|c|c|c|}
\hline & $1^{\text {st }}$ Test & $\begin{array}{c}1^{\text {st }} \text { Nuclear Power } \\
\text { Plant }\end{array}$ & $\begin{array}{c}\text { Time Between 1st Bomb } \\
\text { Test and } 1^{\text {st }} \text { NPP [a] }\end{array}$ \\
\hline USA & 1945 & 1957 & 12 \\
\hline Soviet Union & 1949 & 1954 & 5 \\
\hline Great Britain & 1954 & 1956 & -1 \\
\hline France & 1960 & 1959 & 29 \\
\hline China & 1964 & 1993 & -5 \\
\hline India & 1974 & 1969 & -17 \\
\hline Pakistan & 1998 & 1971 & $>40$ \\
\hline Israel & $\sim 1970^{a}$ & None & $>4$ \\
\hline North Korea & Oct. 2006 & None & \\
\hline
\end{tabular}

${ }^{a}$ Estimate of first weaponisation of plutonium based on US sources, there were no tests in Israel.

${ }^{b}$ Even if electricity production is claimed for a small reactor, this is clearly not at an economic scale.

A look at the history of proliferation, with 9 countries priding themselves of the possession of military nuclear arsenals, clearly shows that the path to the bomb never went through the misuse of civilian nuclear power plants. With the exception of France, India and Pakistan, the first bomb test preceded the civilian power applications for many years or even decades (Table 3 ). In addition, there is no doubt for these countries and the potential candidate Iran that dedicated bomb programs were not at all linked to the power plants and their fuel. However, mastering critical elements of the fuel cycle like ${ }^{235}$ uranium enrichment or reprocessing of spent fuel for separation of fissile ${ }^{239}$ plutonium will give any nation a much shorter track to the bomb. This risk is not contained to the nuclear aspects of an atomic bomb: conventional elements like electronic detonators, high quality explosives and complex engineering are mastered by more and more countries as science and technology further develop. In other words, the technical barriers get lower. This is an important reason to renew efforts on the global scale to tackle the root cause of proliferation. Probably there would be no nuclear Pakistan without the Kashmir problem, Israel is ready to discuss its nuclear status within a comprehensive solution of the Middle East crisis, and the incentives for its neighbours to play or contemplate the nuclear card would be largely diminished. South Africa cannot be commended enough for having been the first and so far only country to give up its bomb arsenal. 
Even if others still have to follow, it is a case in point; with the abolition of Apartheid and the end of isolation, the root cause for needing the bomb had vanished.

Another issue, which is less accessible to scientific and technical reasoning, is nuclear security and the threat of the misuse of radioactive materials by non-state actors, e.g. by the explosion of a dirty bomb, more appropriately defined Radiation Dispersal Device (RDD). Tens of thousands of police, fire fighters and emergency response staff have been trained to respond to scenarios like the combining of a radioactive cancer therapy source with an explosive. However, if a terrorist group would not first grind the source to powder - an acutely deadly endeavour outside a sophisticated hot cell - to mix it with the explosive, assessments show that limited radiological risks would emerge from the dispersion of radioactive material. However, due to perceptions of the media and the public, the centre of a large metropolitan area could be incapacitated for days and remediation costs could be high. For this reason RDDs are also defined as "weapons of mass disruption" to clearly distinguish them from nuclear weapons (weapons of mass destruction).. Even when the threat is real and critical scenarios exist, chemical and biological agents are of greater concern. Especially the latter with the self-propagating power of viruses and bacteria are too scary to be outlined in detail for potential offenders. The writer even has some concerns that training too many to counter a hypothetical threat from RDDs, which fortunately never materialized so far, might increase the probability of having it happen. Society is better served by adopting a proactive approach and searching for science-based solutions. In the case of cancer radiotherapy sources, developmental money could be well spent by replacing the many African radioactive ${ }^{60}$ cobalt sources which save lives on a daily basis by linear accelerators (LINAC). These LINACs come at considerably higher costs but the ionizing radiation can be simply switched off and no radioactivity remains.

Science offers many answers to the triple S of Safety, Security and Safeguards, but whether societies accept residual radiological risks which are sometimes the product of very small probabilities with potentially large impacts, has to come out of political decisions, hopefully based on comparative assessments and informed debate. In a constructive and technical approach, the triple $\mathrm{S}$ of nuclear power can still be improved considerably from present levels by modifying fuel cycles or changing to thorium fission or to fusion, and by the further development of safety culture, standards and quality assurance. 


\section{Understanding the environment}

Environmental radioactivity and stable isotope ratios provide us with unique tools to understand the history and dynamics of planet earth and our environment. This is as important and central for the protection of the environment as radiation medicine is for health care, but not yet widely recognized by the public. Environmental radioactivity has three sources. The first one is primordial radioactivity derived from the early days of the universe. Examples are uranium, thorium and ${ }^{40}$ potassium. They all have half-lives in the range of billions of years, but redistribution processes of shorter-lived daughter products in the uranium and thorium decay chains already provide ample opportunities to study also rapid processes. Diverse and changing chemical properties of actinide oxides for which solubility depends on oxygen pressure to soluble alkaline ions, and finally noble gas radon with half-lives from seconds to days provide a splendid tool box for climate researchers, environmentalists and ecologists. The second source is due to the solar flux from the fusion reactions of our sun. This provides a large multitude of additional radionuclides for atmospheric and marine studies. Well-known radiocarbon, ${ }^{14}$ carbon, with its half-life of 5,730 years does not only permit to trace down welling and deep sea streams of Atlantic waters involved in the Gulf stream, but also the dating of cultural artefacts over the last 25,000 years. The third source is of anthropogenic nature. The pollution of mostly the Northern hemisphere by atmospheric bomb testing mainly in the fifties and sixties of the last century, and of large parts of Europe by the releases from Chernobyl reactor number four, provided tracers to study many elements of the food web relevant to humans. Also, quantitative erosion studies were made possible by ${ }^{137}$ cesium which sticks for decades to undisturbed top soil. The large number of radionuclides present in the environment, their breath of half-lives and chemical behaviour empower the specialist to study and quantify practically any environmental process of importance to humankind.

A further extension based on mass spectrometry and more recently laser technology allows the measurement of ratios of stable nuclides. Enrichment or depletion of nuclides of hydrogen $\left({ }^{1} \mathrm{H} /{ }^{2} \mathrm{H}\right.$ : a weight difference of a factor of two), carbon $\left({ }^{12} \mathrm{C} /{ }^{13} \mathrm{C}\right)$ nitrogen $\left({ }^{14} \mathrm{~N} /{ }^{15} \mathrm{~N}\right)$ and oxygen $\left({ }^{16} \mathrm{O} /{ }^{18} \mathrm{O}\right)$ is dependent on temperature and number of phase transitions (e.g. evaporation/condensation). The resulting fingerprints of water samples from different location reveal many secrets of regional and global water cycles, and form the basis for the sustainable management of scarce resources. 
Table 4: Understanding the environment with nuclear tracers. Examples of important tracer and applications.

\begin{tabular}{|c|c|c|c|}
\hline Nuclide & Half-life & Natural form & Important applications \\
\hline${ }^{14}$ carbon & $5730 \mathrm{a}$ & $\begin{array}{l}\mathrm{CO}_{2} \text { gas and organic } \\
\text { matrices }\end{array}$ & $\begin{array}{l}\text { Dating of human remains, organic } \\
\text { structures, cultural artefacts, iso- } \\
\text { lation time of waters from atmo- } \\
\text { sphere }\end{array}$ \\
\hline 137 cesium & $30.17 \mathrm{a}$ & Alkaline ion & $\begin{array}{l}\text { Metabolism of alkaline elements, } \\
\text { quantification of soil erosion }\end{array}$ \\
\hline${ }^{222}$ radon & $3.83 \mathrm{~d}$ & Noble gas & $\begin{array}{l}\text { Transport of soil gas, quantifi- } \\
\text { cation of submarine groundwater } \\
\text { discharge, earth quake prediction? }\end{array}$ \\
\hline${ }^{210}$ lead & $22.3 \mathrm{a}$ & $\begin{array}{l}\text { Emerging from }{ }^{222} \text { radon } \\
\text { decay, first bound to air- } \\
\text { borne particles, then in } \\
\text { sediments }\end{array}$ & $\begin{array}{l}\text { Atmospheric mixing, dating of } \\
\text { sediments }\end{array}$ \\
\hline${ }^{3}$ hydrogen & $12.32 \mathrm{a}$ & $\mathrm{H}_{2} \mathrm{O}$ (water) & $\begin{array}{l}\text { Global atmospheric mixing after } \\
\text { bomb tests, water cycle, age of wa- } \\
\text { ter, wine }\end{array}$ \\
\hline $1 / 2$ hydrogen ratio & - & Water/ice/water vapour & $\begin{array}{l}\text { Water cycle, climate and tempera- } \\
\text { ture records }\end{array}$ \\
\hline
\end{tabular}

The following examples are not comprehensive but show the width of nuclear applications in environmental studies. Understanding the reservoirs and flows of carbon dioxide, the primary greenhouse gas after water vapour, that regulates the global heat balance on earth in quantitative terms is an urgent necessity for efficient mitigation or adaption to climate change. Anthropogenic $\mathrm{CO}_{2}$ from fossil burning is devoid of ${ }^{14}$ carbon and hence can be followed with this marker. The ocean absorbs $\mathrm{CO}_{2}$ through physical as well as biological processes, namely through photosynthesis by microalgae (phytoplankton), ingestion of phytoplankton by microscopic animals (zooplankton), and eventual settling of that carbon into the abyss. The infiltration of fossil carbon into the ocean, which is due to physical processes, has been tracked by ocean measurements of carbon isotopes $\left({ }^{12} \mathrm{C},{ }^{13} \mathrm{C}\right.$ and $\left.{ }^{14} \mathrm{C}\right)$. These isotopic data can provide quantitative assessments, e.g. that the ocean is currently absorbing about 2 gigatonnes per year of anthropogenic $\mathrm{CO}_{2}$, which is about one third of the total annual anthropogenic $\mathrm{CO}_{2}$ emissions from fossil fuel burning and deforestation.

Dating sediments or studying ocean current systems is again made possible with radionuclides. The natural radionuclide ${ }^{210}$ polonium with a half-live of 22 years derives from airborne ${ }^{222}$ radon, is bound to marine particles and deposited together with other pollutants. The radionuclide concentration in the different layers of the sediment allows to study the temporal input 
of pollutants over time, in this case for about 150 years of industrial pollution. Traces from various sources of radioactive substances are found at long distances from their input. These data can be used for ocean circulation studies. ${ }^{137}$ Cesium and ${ }^{14}$ carbon were determined in vertical profiles in the Southern Hemisphere covering the Atlantic, Indian and Pacific Ocean. By this technique, the vertical penetration of water masses into the ocean and the renewal time for deep ocean water from different origin can be studied. The existence of a rapid transport from surface Pacific Ocean water into the Indian Ocean was found by this method.

Considerable amounts of fresh water enter the sea through subsurface aquifers. Estimates of this so-called submarine groundwater discharge (SGD) vary significantly between $6 \%$ and $100 \%$ of the river basin inputs which is largely due to the regional and temporal variability of SGD. SGD has received considerable attention in coastal management for several reasons: First, SGD is a potential freshwater resource in areas with water shortage; if SGD is composed of brackish water it may be utilised in desalinisation plants; thirdly, SGD may be associated with high contents of pollutants (nutrients, metals, pesticides) thus effecting coastal ecosystems. Outbreaks of harmful algae blooms and contamination of coastal regions are some of the consequences. The quantification of submarine groundwater discharge helps to prevent over-exploitation of and salt water intrusion in coastal aquifers. Radium and radon measurement techniques have been developed to detect and to quantify SGD in coastal regions in view of sustainable water resource management.

\section{The water cycle and climate}

Clean water and sanitation is the most basic human need addressed in the Millennium Development Goals. Both water and environmental issues are emphasized in order to achieve sustainable development. In 2002 this global commitment to sustainable development was once again addressed at the World Summit on Sustainable Development (WSSD) in Johannesburg. Here a comprehensive review and assessment of the progress achieved since Rio was carried out resulting in recommendations for future actions for the preservation of the sea and fresh waters, soil, air and other natural resources even in a future predicting large increases in industrial and agricultural production. The UN continues to emphasize the importance of sustainability and a healthy environment as exemplified by the establishment of the "Water for Life Decade" (2005-2015). In response to these and other calls for 


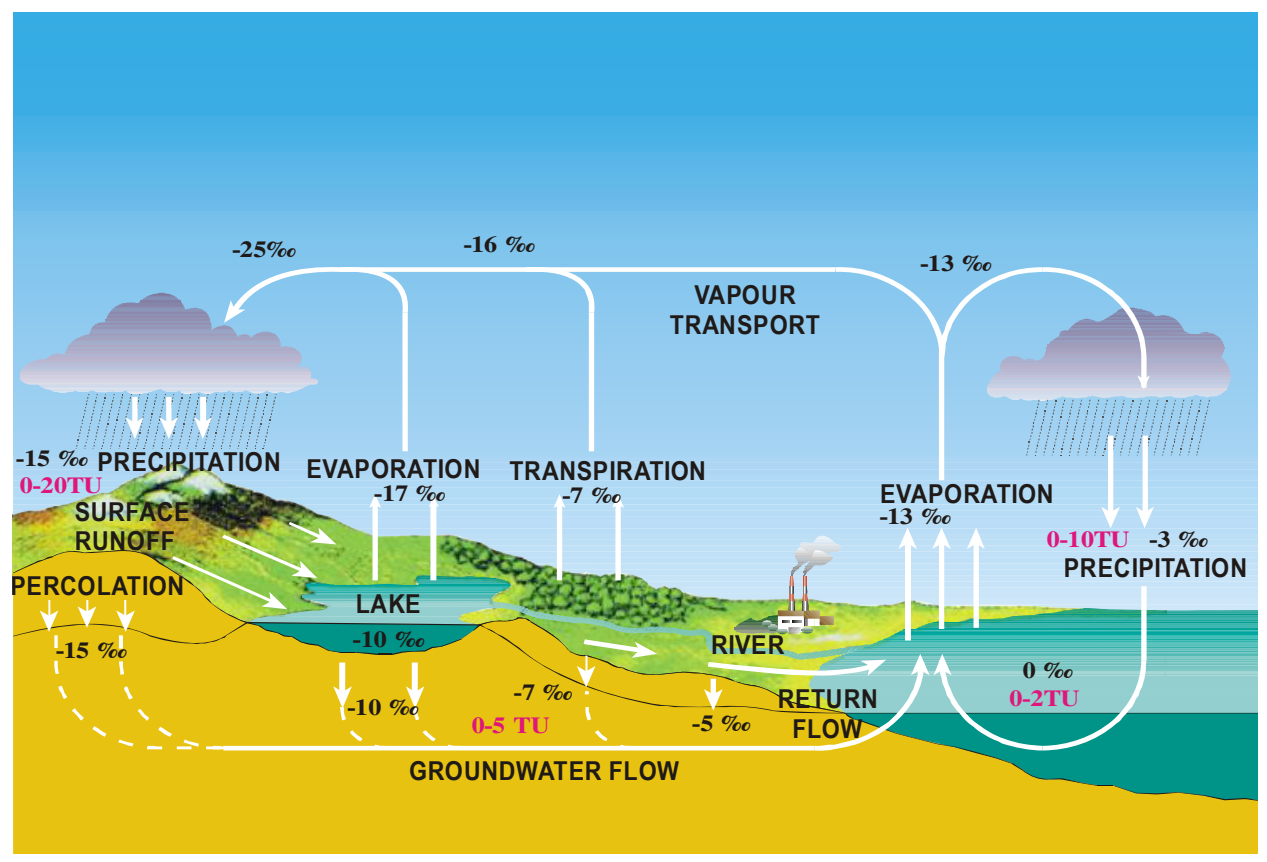

Figure 1: Oxygen stable isotope ratios and tritium values along the water cycle.

action, IAEA and others have worked to expand the use of nuclear techniques to address water and environment problems for many decades. The establishment of the UN Millennium Development Goal (MDG) \#7 to "ensure environmental sustainability" highlights the urgency and severity of water and environmental issues around the world. In addition, the growing evidence of the scale of climate change, its related economic, social and ecosystem impacts, as well as its potentially irreversible nature, is one of the most formidable challenges that the world will face in the years to come. Nuclear technology provides the key to the understanding and quantification of several climate change issues. This is especially true for the water cycle which plays a central role in nearly all of the current and emerging environmental problems that need to be addressed by our global society. As shown in the figure 1, the water cycle links the marine environment to the atmosphere, and the atmosphere in turn links to the terrestrial environment. Groundwater and surface water discharges from the terrestrial environment into the world's oceans complete the cycle. These linkages between the marine and terrestrial environments and the atmosphere, and the processes affecting water cycling within these three components determine heat and 
mass flows on the local and global level, and determine solar and infrared radiation balance and hence weather and climate. However, a proper understanding of water cycle processes was hampered until the advent of nuclear methods which provided a powerful set of stable isotope tools for "fingerprinting" various parts of the water cycle and radioactive isotope tools for dating water. Isotope hydrology uses of natural and anthropogenic isotopes, both stable and radioactive, such as ${ }^{2} \mathrm{H},{ }^{18} \mathrm{O},{ }^{3} \mathrm{H},{ }^{14} \mathrm{C}$ etc., as tracers to study, manage and develop water resources. These are natural indicators for water flow, direction, travel times, and age of water bodies. Isotope hydrology has considerably extended our knowledge of the water cycle beyond the information derived from water chemistry and conventional hydrological methods.

The fingerprinting is based on the fact that water molecules are made up of two different hydrogen and oxygen stable isotopes, respectively, and that the isotope ratios of water samples can be measured using a mass spectrometer. The history and pathway of water in different parts of the hydrological cycle can be followed by the abundance of the stable heavy isotopes of hydrogen $\left({ }^{2} \mathrm{H}\right.$ : deuterium) and oxygen $\left({ }^{18} \mathrm{O}\right)$. In this way, water in different environments develops isotopic "fingerprints" with which it can be identified and its origins traced. Isotope fractionation is a change in isotopic composition in the transition of a compound from one state to another (e.g. liquid water to water vapour) or into another compound (e.g. carbon dioxide into plant organic carbon). The partitioning of isotopes between substances during reactions or processes can be used to characterize processes in the biological, geological, and hydrological realm, both past and present. Isotope fractionation is governed by the principle that lighter isotopes, or species with a lower molecular weight, will be favoured in evaporation processes and biological uptake, leaving the source material "heavier," or with the heavier isotope more abundant. Light elements exhibit greater isotopic fractionation than heavy isotopes because the relative mass difference from additional neutrons is higher, i.e. $100 \%$ between ${ }^{1} \mathrm{H}$ and ${ }^{2} \mathrm{H}$, or $12.5 \%$ between ${ }^{16} \mathrm{O}$ and ${ }^{18} \mathrm{O}$. These relative differences drive stable isotope fractionation. Therefore, isotopes especially susceptible to substantial fractionation belong to the light elements that are among the most abundant on earth: H, C, N, O, and S.

Models of isotopic variability take into account: vapour pressure, humidity, temperature, altitude, rainout and moisture content, evaporation and solute concentration, and combinations thereof. In studies of the water cycle, $\mathrm{O}$ and $\mathrm{H}$ and their isotopic fractionation characteristics are usually considered together. As a result of fractionation, waters develop unique isotopic compositions that can be indicative of their source or the processes 
that formed them. The fundamental control on the isotopic composition of precipitation is temperature. With increasing temperature, precipitation becomes enriched in the heavier isotopes ${ }^{18} \mathrm{O}$ and ${ }^{2} \mathrm{H}$, in a linear relationship. Temperature affects fractionation at a rate of approximately $0.5 \%$ for every $\mathrm{C}^{\circ}$ for oxygen. Similar effects are shown with increasing elevation and increased distance from the equator (both of which correspond to lower temperature). Because precipitation becomes progressively enriched in light oxygen as it moves toward the cold polar regions, polar ice constitutes a reservoir of ${ }^{16} \mathrm{O}$ enriched water as compared to sea water. Because the isotopic ratios ${ }^{18} \mathrm{O} /{ }^{16} \mathrm{O}$ and ${ }^{2} \mathrm{H} /{ }^{1} \mathrm{H}$ have a strong positive correlation with temperature, their measurements in ice cores are valuable indicators of climate variability.

Figure 1 shows ratios change as water is moving through different compartments making up the water cycle. Stable isotopes are reported as permil values (\%) and the figure shows how ${ }^{18}$ oxygen isotope values change through the water cycle. As an example, the effect of evaporation is clearly shown on the right side of the figure where isotope values are shifted from $0 \%$ in the ocean to $-13 \%$ in the atmosphere. These stable isotope fingerprints help us not only understand how the water cycle functions, but are also used to determine other difficult to obtain environmental and water management information such as the elevation of groundwater recharge (renewal) zones so that adequate protection areas can be established. Sources and locations of subsurface water entering rivers and lakes, mixing of different groundwater bodies, and sources and depths of water utilized by plants can be identified. They can even help us to understand past and current climate patterns. It is also noteworthy that stable isotopes of other elements such as nitrogen can be used to identify sources of pollution.

In earlier times artificial radionuclides were occasionally introduced to trace a particular environmental process. Today environmental studies rely on measurements of radionuclides that are already present in the environment naturally or from human activities. Tritium, ${ }^{3}$ hydrogen, and its stable decay product ${ }^{3}$ helium are central for the elucidation of the water cycle. The figure also shows how tritium incorporated into water molecules moves through water compartments (units are given as tritium units or TU). Through the specific activity of tritium and ${ }^{14}$ carbon which is a measure of the time of isolation of the water sample from the atmosphere, water bodies, especially groundwater, can be dated. Prior to the application of such tracers it was not apparent that many groundwater bodies had ages of more than 10,000 years. In fact, the Nubian aquifer in North Eastern Africa contains water that is about 1 million years old. Identifying these old water 
systems is important because they can be large and provide quality groundwater supplies, but they have to be managed differently than systems where groundwater renewal occurs over short time scales. These have been just a few examples of the broad application of nuclear techniques to the water cycle. A key concept is that by tracking the isotopes of water, scientists can quickly obtain valuable information which would otherwise require decades of data collection or may not be obtainable at all. The use of isotopes is rapidly growing in all environmental areas and is leading to much greater insights about the complex processes that must be understood in order to address the wide variety of environmental issues facing society today. Thus again, nuclear will play a significant role in the quest to meet the UN environmental MDGs and to manage our planet in a sustainable way.

The author is indebted to Piero Danesi, former Director of the IAEA laboratories at Seibersdorf, Austria, for technical input and review. 